\title{
PÓS-GRADUAÇÃO NA ÁREA DA ECOLOGIA: UMA ANALISE DAS LINHAS DE PESQUISA NA FORMAÇÃO DAS REDES DE COOPERAÇÃO
}

\section{POSTGRADUATION IN AREA OF THE ECOLOGY: AN ANALYSIS OF RESEARCH LINES IN FORMATION OF COOPERATION NETWORKS}

\author{
Camila Ferreira Pinto das Neves 1 , Gionara Tauchen ${ }^{2}$ \\ ${ }^{1}$ Universidade Federal do Rio Grande/Instituto de Educação/camilapinto.eco@gmail.com \\ ${ }^{2}$ Universidade Federal do Rio Grande/Instituto de Educação/giotauchen@gmail.com
}

\section{RESUMO}

Neste artigo são analisadas algumas aproximações e os distanciamentos das linhas de pesquisa que integram os programas de pós-graduação na Área do conhecimento Ecologia, com o objetivo de prospectar possibilidades de cooperação entre os programas. A Análise de Conteúdo foi a metodologia utilizada. Para identificarmos as linhas de pesquisa, resgatamos dos programas de pós-graduação na Área do conhecimento em Ecologia, particularmente no ano de 2013, os seus cadernos de indicadores. Neste sentido, através da análise das ementas das linhas foi possível a organização de vinte categorias. Os resultados apontam que as linhas de pesquisa ecologia de populações e comunidades; ecologia e conservação; ecologia e manejo da biodiversidade são as mais fortalecidas e vem dominando os estudos na Área da Ecologia.

Palavras-chave: Ecologia. Cooperação. Linhas de pesquisa. Pós-graduação.

\begin{abstract}
This paper aims at analyzing some approximations and detachments of lines of research which integrate post-graduation programs in respected to the knowledge of Ecology Area, aiming at prospecting possibilities of cooperation between the programs. Analysis of Content was the methodology adopted. We rescue programs of post-graduation in respected to the knowledge in Area of the Ecology, particularly in the year of 2013, and his exercise books of indicators to identify his lines of inquiry. In this sense, through the analysis of the menus of the lines the organization of twenty categories was possible. The results have revealed the most strengthened lines in the programs of postgraduation in the Ecology Area is population and communities of ecology; ecology and preservation; ecology and biodiversity management, insinuating which knowledge has been dominating the Ecology studies.
\end{abstract}

Keywords: Ecology. Cooperation. Lines of research. Post-Graduation.

\section{INTRODUÇÃO}

Atualmente, há um grande crescimento dos estudos sobre a Ecologia no Brasil. Na década de setenta, quando emergiu a pós-graduação nesta Área, existiam apenas seis programas, e hoje, três décadas depois, segundo dados da Coordenação de 
Aperfeiçoamento de Pessoal de Nível Superior - CAPES, a Área conta com noventa e seis programas distribuídos em nível de Mestrado Acadêmico, Mestrado Profissional e Doutorado (CAPES, 2014).

Os programas de pós-graduação, em sua composição, são formados por linhas de pesquisas, as quais orientam os estudos direcionados à finalidade particular de cada linha. Neste contexto, a linha de pesquisa representa temas de estudos científicos que se fundamentam em tradição investigativa, de onde se originam projetos cujos resultados guardam afinidades entre si (UFPEL, 2014).

No entanto, tem-se observado, de forma crescente, o aparecimento de linhas de pesquisas comuns, ou semelhantes, em programas de instituições diferentes, inclusive na Área do conhecimento Ecologia, por exemplo, por meio da linha de pesquisa Ecologia de Ecossistemas, a qual aparece no Instituto Nacional de Pesquisas da Amazônia - INPA e na Universidade de Brasília - UnB.

A capacidade de cooperação entre os programas faz com que pesquisadores que investigam em uma determinada linha possam partilhar seus conhecimentos com outros que investigam em uma linha comum. Sendo assim, estes sujeitos podem unir seus conhecimentos e fortalecer uma Área de pesquisa e assim promover um uma coletividade científica. Com maior 'proximidade', os sujeitos podem refletir sobre um problema sem mais estar em um território 'limitado'. Segue-se que o aspecto geográfico da localização dos cursos não interfere negativamente, pois a cooperação inclui uma rede de relações entre os atores posicionados em regiões distintas. Nas palavras de Sobrino (2011), a coletividade científica se reflete em um esforço adicional na capacidade de os representantes influenciarem na imposição ao campo de problemas, métodos e teorias científicas.

Particularmente, neste estudo sobre as linhas de pesquisa dos programas de pós-graduação na Área do conhecimento Ecologia entenderemos cada programa e linha como expressão dos interesses e organização das respectivas comunidades científicas.

Por isso, o objetivo deste trabalho é analisar a potencialidade das redes de cooperação entre os programas de pós-graduação por meio da analise das linhas de pesquisa, ampliando as compreensões sobre a organização das comunidades científicas na Área do conhecimento Ecologia. 


\section{FUNDAMENTAÇÃO TEÓRICA}

O termo "coletivo de pensamento" surgiu, originalmente, nos estudos do Ludwik Fleck (1935). No entanto, autores como Thomas Kuhn (1962), Luiz Carlos Bombassaro (1995), Edgar Morin (2005), entre outros, contribuíram com os estudos sobre o tema, o que nos auxilia a compreender as dinâmicas de organização das comunidades científicas. Conforme Fleck (1986), o termo 'comunidade científica' assemelha-se ao de "coletivo de pensamento" ${ }^{1}$ Para o autor, o portador do estilo de pensamento é o pensamento coletivo, isto é, o sentido e o valor do 'descobrimento' estão na comunidade daqueles que mantêm uma interação entre seus pensamentos, baseada em um passado intelectual compartilhado, de modo que conhecer é, principalmente, constatar os resultados impostos por certas pressuposições, coletivamente dadas, em um determinado período da história das ideias. Para Schnelle (1986), o coletivo de pensamento é a unidade social do estilo de pensamento, sendo composto por indivíduos que compartilham as mesmas ideias, conceitos e teorias. E, no entendimento de Parreiras (2006, p. 69), “nessa dinâmica, o indivíduo, que está subordinado ao coletivo, contribui para ocorrência do novo, juntamente com os outros companheiros, com suas ideias, experiências e constatações".

Thomas Kuhn (2009) também trata da noção de 'comunidade científica', enraizado em sua concepção de ciência. Para o autor, não se faz ciência sozinho, pois "a ciência é a união de fatos, teorias e métodos reunidos através de esforços coletivos explanados em textos atuais" (KUHN, 2009, p. 20). Dito de outro modo, "a ciência é uma tarefa coletiva que se desenvolve a partir das realizações das gerações anteriores" (BOMBASSARO, 1995, p. 42). Isto é, a ação investigadora e coletiva dos cientistas se faz nas comunidades científicas.

Grifos de Kuhn (2009, p. 222) sugerem que "as comunidades investigativas são formadas pelos praticantes de uma especialidade científica". Convém acrescentar a importância destes grupos, dedicados a uma especialização do conhecimento, que dialogam entre comunidades afins e, ao mesmo tempo, publicizam os conhecimentos para que amplie, efetivamente, uma área do conhecimento. Segundo Martins (2007), a maneira pela qual isso se realiza é materializado nas teses e nas dissertações, que são o produto resultante das pesquisas na pós-graduação.

\footnotetext{
${ }^{1}$ Não pretendemos nos aprofundar no pensamento Fleckiano e sim complementar nossa discussão com o termo 'coletivo de pensadores' atribuído pelo filósofo Ludwick Fleck, em 1935. Este autor defende a ideia de que o saber é construído sócio e historicamente.
} 


\section{Ensino, Saúde e Ambiente - V7 (3), p. 70-83, Dez. 2014}

Para Kuhn (2009 pg. 80), “as comunidades de investigação organizam-se em torno deste elemento básico que é o conhecimento já produzido e considerado indispensável aos seus membros". Compartilhar os fundamentos epistemológicos é o que promove, sustenta uma epistemologia. Particularmente, não podemos deixar de somar as contribuições de Edgar Morin (2005, p. 181), para quem as comunidades científicas são preenchidas pelas nossas "sociedades históricas contemporâneas que se auto-organizam não só a partir de um centro de comando-decisão [...], mas também de diversos centros de organização [...] e de interações espontâneas entre grupos de indivíduos".

Assim, é possível entender as comunidades científicas como grupos constituídos por indivíduos que compartilham ideias, conhecimentos e referenciais epistemológicos e metodológicos.

Compreender os interesses partilhados pelas comunidades científicas nos auxilia a perceber como as suas preocupações temáticas, na Área do conhecimento Ecologia, podem fortalecer um coletivo de pensamento. Essas aproximações podem ser construídas por meio do mapeamento de interesses comuns evidenciados através das linhas de pesquisa que integram os programas de pós-graduação.

É importante notar que as linhas de pesquisa incorporam os interesses das comunidades científicas ligadas à Área de pesquisa estudada. Por exemplo, as linhas dos programas da Área do conhecimento Ecologia são constituídas por comunidades científicas que se dedicam a pensar, discutir, compartilhar suas pesquisas e, fruto disso, é a produção de novos conhecimentos que contribuem com a consolidação e estruturação da Área. Para Martins et. al. (2007), este diálogo não deve se dar de forma isolada, mas, sim, em redes de cooperação entre os programas de pós-graduação que integram a Área do conhecimento Ecologia, pois a Ecologia é uma ciência que abraça todas as ciências e a cooperação contribui para a evolução não só de uma Área, mas de diversas Áreas. Para Morin (2011), a ciência ecológica formula-se em um contexto global, e converte-se em uma ciência/consciência planetária, que concerne a toda humanidade. Uma consequência, pois, é que a Ecologia está em sua plena abertura planetária, englobando as inter-retroações, propondo nova consciência ecológica que não pode ser fechada para o mundo, mas, sim, aberta a uma cooperação em toda sua amplitude antropoecoplanetária (MORIN, 2011). 
Segundo French (2009 p. 132), “o conhecimento científico é construído através da interação social, ou seja, através de uma forma de negociação entre especialistas nos seus espaços formais". Ainda, para este autor, os padrões sociais podem limitar ou ampliar os fatos científicos que são vistos como socialmente construídos, por exemplo, "os fatos dependem do contexto social, então um contexto social diferente (em uma época diferente ou em um lugar diferente) conduzirá a um conjunto diferente de fatos e de um conhecimento científico diferente" (idem, ibidem). Por exemplo, cada investigação agrupada a uma linha de pesquisa terá a sua particularidade relacionada ao correspondente sujeito investigativo.

Segundo (ANDRADE, 2003), o conceito de linhas de pesquisa sofreu vários problemas de definição, pois partem de uma unidade de análise para a avaliação de cursos e de propostas de cursos que se direcionam por cálculos de projetos, pesquisadores, alunos, publicações e dissertações por linhas, grupos e linhas de pesquisa, além de áreas de concentração, etc. Assim, para o autor, a linha de pesquisa,

\footnotetext{
determina o rumo, ou o que será investigado num dado contexto ou realidade; limita as fronteiras do campo específico do conhecimento em que deverá ser inserido o estudo; oferece orientação teórica aos que farão a busca; e estabelece os procedimentos que serão considerados adequados nesse processo (ANDRADE, 2003, p. 164).
}

As linhas de pesquisa surgiram como a finalidade de superar o modelo antigo, denominado Áreas de concentração (GAMBOA 2003), muito embora ainda permaneçam como unidade de integração das linhas de pesquisa. Conforme Gamboa (2003, p. 80), “as Áreas de concentração exigem uma delimitação técnica dos campos do conhecimento e supõem um olhar recortado dos problemas e uma visão segmentada e mecânica do mundo". Este modelo esconde a complexidade dos problemas estudados nas pesquisas. Neste novo molde, as linhas de pesquisa expressam as dimensões e o desejo dos programas, e sugere:

situar a pesquisa em um eixo da Pós-graduação "que articulam interesses de diversos pesquisadores, propiciando o trabalho interdisciplinar, a contribuição de diversas visões, diferentes abordagens teórico metodológicas e o concurso de diversas tradições epistemológicas (GAMBOA, 2003, p. 03).

A organização em linhas de pesquisa ganhou espaço desde a década de noventa, com a finalidade de superar o molde anterior, que estava organizado em Áreas 
de concentração. Conforme Gamboa (2003), a finalidade era tratar dos problemas coletivamente e agrupar os pesquisadores, oriundos de áreas, departamentos e unidades acadêmicas diferentes, preocupados com a compreensão de um determinado problema comum, reduzindo as divisões impostas pelo modelo anterior. Esse novo modelo sugere a criação de grupos de pesquisa, os quais reúnem sujeitos de diversos níveis acadêmicos e de formação em Áreas distintas, para juntos debaterem um problema comum vinculado à linha. Atualmente, há, vinculado, aos programas de pós-graduação, grupos de pesquisas que compartilham suas compreensões a respeito de uma temática comum ${ }^{2}$, o que remete a uma rede de cooperação.

O Sistema Nacional da Pós-Graduação (SNPG) ampliou seus olhares a outras formas de apropriação do conhecimento científico e, neste novo ciclo de desenvolvimento, sugere a formação de redes cooperativas de pesquisa. Neto (2010) aponta que a CAPES vem apoiando vários modelos de redes como, por exemplo, o PROCAD (Programa de Cooperação Acadêmica), parcerias para a realização de mestrados e doutorados interinstitucionais (Minter e Dinter), grandes associações (redes multicentros) e outras formas de associação.

Segundo Neto (2010, p. 60), “a crescente complexidade do desenvolvimento científico, as rápidas mudanças na efetividade das políticas de educação, ciência e tecnologia e os custos das atividades de pesquisa e pós-graduação movimentam a organização de redes cooperativas”. As redes de cooperação são formadas por grupos de pesquisadores que se dedicam a um estudo do mesmo interesse. As redes de cooperação propiciam, também, que regiões geograficamente dispersas possam unir esforços com a mesma finalidade, formando grupos maiores, equipes diversificadas para o desenvolvimento de um conhecimento complexo, emergentes ou em evolução.

A complexidade da Área do conhecimento Ecologia estimula novos conhecimentos em múltiplos campos e, às vezes, o surgimento de um campo novo é característico da interação entre os pesquisadores com semelhanças de estudo. Por isso, estudar as aproximações entre as linhas e nos permite identificar possíveis cooperações entre os programas, tratando o conhecimento não mais de forma local e sim

\footnotetext{
${ }^{2}$ Tomamos, como exemplo de rede de estudos, os programas de pós-graduação em Educação em Ciências: Química da Vida e Saúde, o qual fazem interlocução entre a UFSM, UFRGS e FURG. E, em grupos de estudos, a Rede de Estudos e Pesquisas em Educação Superior - REPES. Esta congrega pesquisadores de universidades distintas como a FURG, UnB, UPF e UNIPAMPA, que desenvolvem estudos e pesquisas sobre os processos de formação docente, epistemologia e processos pedagógicos, inovação, gestão e políticas de avaliação, organização e produção do conhecimento na pós-graduação.
} 
socializando as informações entre os pesquisadores que partilham de um mesmo interesse científico. Além disso, atendem aos aprofundamentos temáticos da respectiva área em questão, evitando a perda de originalidade da pesquisa (NETO, 2010).

\section{METODOLOGIA}

A metodologia utilizada para análise dos dados foi a Análise de Conteúdo (BARDIN, 2011). A Análise de Conteúdo organiza um conjunto de instrumentos técnicos de validação que se aplicam a discursos linguísticos ${ }^{3}$ que estão 'ocultos' aos olhos da interpretação. Esta metodologia de análise organiza-se em torno de três eixos cronológicos: 1) Pré-análise: momento em que o pesquisador escolhe os documentos a serem analisados, a formulação das hipóteses e dos objetivos e a elaboração de indicadores que fundamentem a interpretação final. 2) Exploração do material: momento de operar e codificar o material. Esta etapa é definida como "o processo pelo qual os dados brutos são transformados sistematicamente e agregados em unidades, as quais permitem uma descrição exata das características pertinentes do conteúdo" (BARDIN, 2011, p. 133). Para isso, o pesquisador tem três opções: o recorte (escolha das unidades), a enumeração (escolha das regras de contagem) e a classificação e agregação (escolha das categorias). 3) Tratamento dos resultados, a inferência e a interpretação: neste eixo, o sujeito escolhe qual é a melhor maneira de apresentar os resultados da pesquisa. Assim, podem apoiar-se em operações estatísticas, gráficos, tabelas, etc. A interpretação pode sugerir outras orientações para uma nova análise ou utilização dos resultados com fins teóricos ou pragmáticos.

Conforme as descrições acima, articulamos as etapas deste estudo em três passos:

1) Dos programas de pós-graduação: consultamos o sítio eletrônico da CAPES para o levantamento dos programas pós-graduação situados na área do conhecimento Ecologia em nível de doutorado, tomando como referência o ano de 2013 (CAPES, 2014a).

2) Das linhas de pesquisa: Resgatamos no site da CAPES os cadernos de indicadores dos programas para identificarmos as linhas de pesquisa que serviram para a

\footnotetext{
${ }^{3}$ Discursos escrito, oral, iônico (fotografias, filmes, sinais, imagens e grafismos) ou códigos semióticos (tudo que não é linguístico e pode ser portador de significados, por exemplo: músicas, objetos, sinais patológicos etc.).
} 
análise. Nesta ação, buscamos o nome da instituição, nome da linha de pesquisa e a ementa.

3) Tratamento dos dados: o agrupamento das linhas semelhantes foi realizado sobre a análise dos dados, o que gerou uma categorização entre as linhas comuns. As linhas que não possibilitaram o agrupamento por similaridade foram colocadas na categoria 'outros'.

A partir do levantamento das categorias vislumbramos possíveis redes de cooperação, expressando os que têm maior e menor aproximação.

\section{ANÁLISE DOS DADOS E DISCUSSÃO}

A pós-graduação brasileira consta, atualmente, com 3.793 (três mil setecentos e noventa e três) programas de pós-graduação e 49 (quarenta e nove) Áreas de avaliação (CAPES, 2014b). A Área do conhecimento Ecologia é integrada por 95 (noventa e cinco) programas: Mestrado Acadêmico (56), Mestrado Profissional (4) e Doutorado (35), todos distribuídos em regiões distintas no Brasil (Figura 01).

Figura 01: Distribuição geográfica dos cursos de doutorado na Área do conhecimento Ecologia.

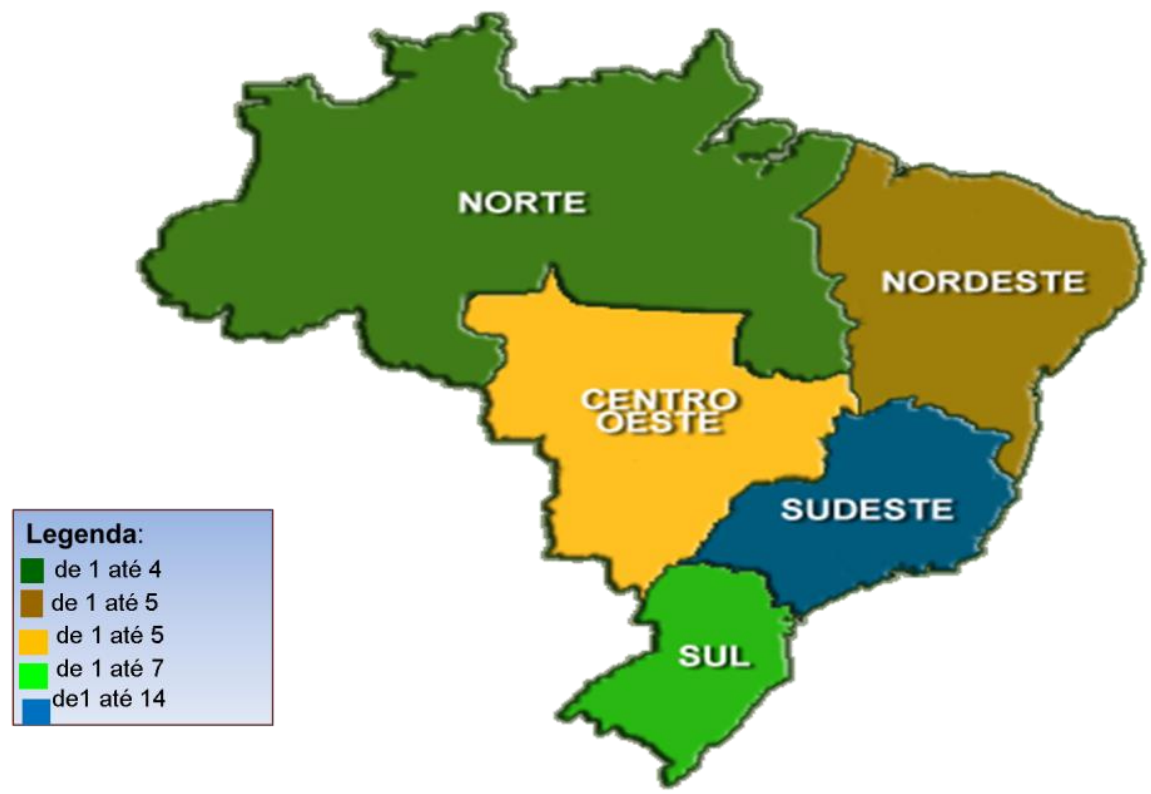

Fonte: CAPES.

Os dados evidenciam grande concentração de programas nas regiões Sudeste e Sul do País. Podemos observar que a região Norte e Nordeste são as menos contempladas com estes cursos, evidenciando necessidade do desenvolvimento de 
programas de pós-graduação na Área do conhecimento Ecologia nessas regiões. Destacamos que essas regiões são as que possuem uma grande diversidade de riqueza natural, as quais servem para as investigações na Área da Ecologia. Independentemente da região na qual programa está inserido, foram localizados programas em todas as regiões do Brasil. A Tabela 01, abaixo, representa os 35 (trinta e cinco) cursos de Doutorado, que se encontram distribuídos do mapa acima.

Tabela 01: Cursos de doutorado na Área do conhecimento Ecologia por região.

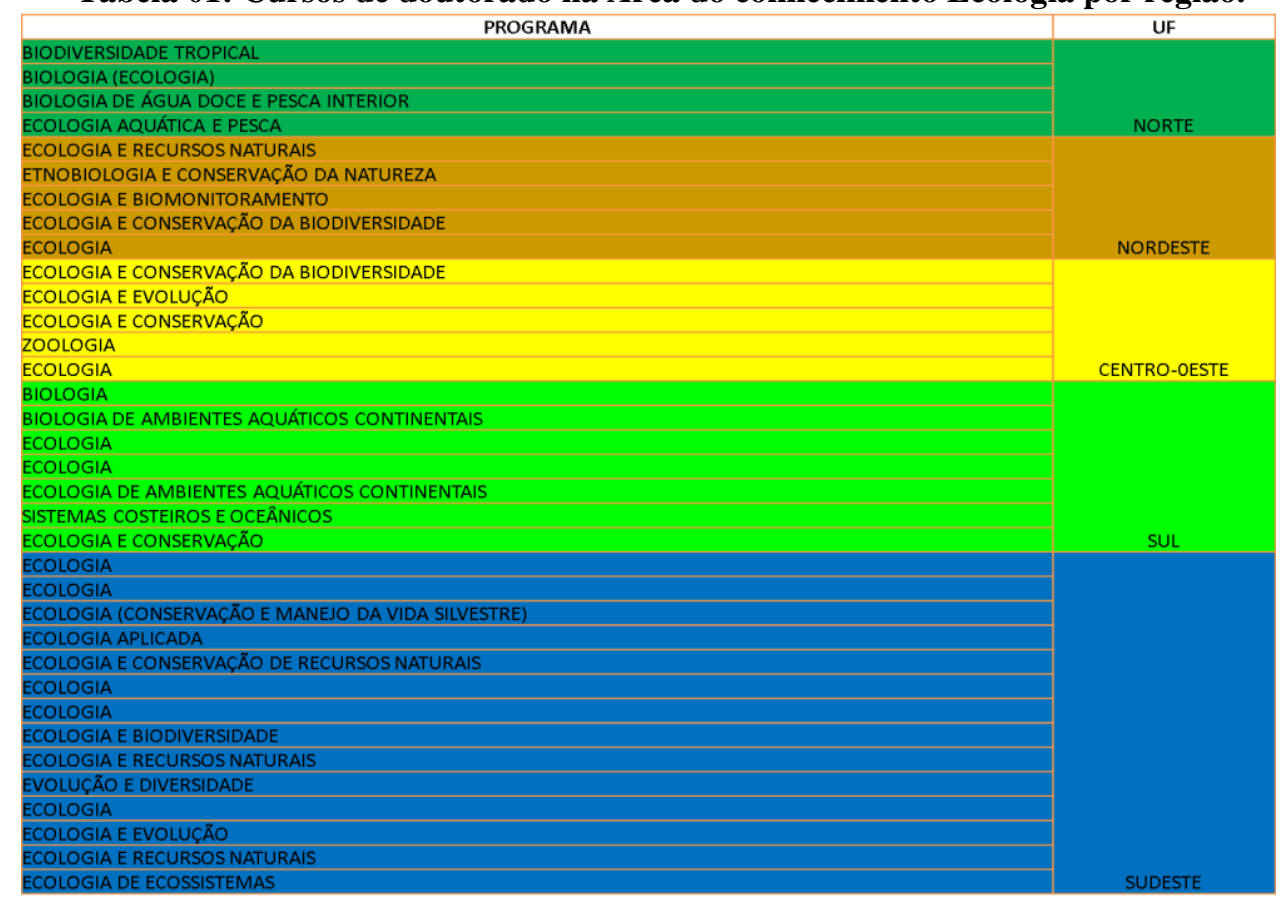

Fonte: CAPES ${ }^{4}$.

Na última Avaliação Trienal da CAPES (2010-2012), os programas que compõem o estudo informaram 139 (cento e trinta e nove) linhas de pesquisa. Nossa análise sobre a descrição das linhas permitiu identificar aproximações entre os programas, organizando a categorização que segue (Tabela 02).

\footnotetext{
${ }^{4}$ Todas as informações aqui apresentadas foram obtidas no site da CAPES, no entanto, a organização dos gráficos e tabelas é da autora.
} 
Tabela 02: Categorias decorrentes da análise das linhas de pesquisa dos programas de pós-graduação na Área do conhecimento Ecologia.

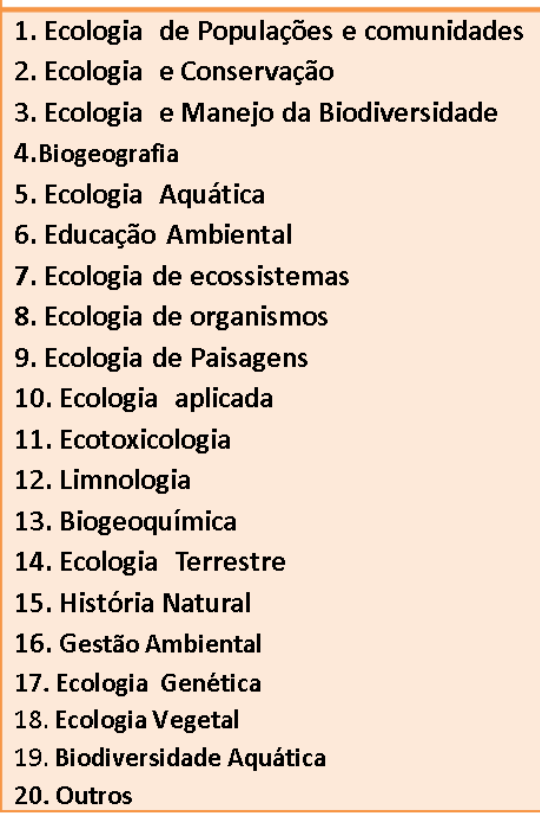

Fonte: CAPES.

Compreendemos que os programas de pós-graduação na Área do conhecimento Ecologia indicam propostas similares e que, mesmo sendo separados regionalmente, podem aproximar-se por interesse de estudo, possibilitando uma rede coletiva de pensamento. Esta análise expressa a possibilidade de os programas trabalharem coletivamente, em cooperação, expandindo a produção e o avanço do conhecimento e da pós-graduação na Área da do conhecimento Ecologia. Esta compreensão também contribui para compreendermos quais temáticas estão dominando os estudos na Área da Ecologia. Neste entendimento, as linhas de pesquisa ecologia de populações $e$ comunidades; ecologia e conservação; ecologia e manejo da biodiversidade foram as mais incidentes entre os programas investigados, num total de nove programas. Outras linhas que se destacam são: biodiversidade e ecologia aquática, possibilitando rede de cooperação entre sete programas. Este pode ser um indício de que as pesquisas na Área do conhecimento Ecologia estão sendo desenvolvidas, em grande parte, nos eixos temáticos das linhas citadas acima. Com menor similaridade entre as categorias estão as linhas de pesquisa ecologia terrestre; história natural; gestão ambiental; ecologia genética; ecologia vegetal e biodiversidade aquática.

A Figura 02 representa a aproximação das linhas entre os programas, o que possibilitou o levantamento do potencial de cooperação entre eles. Neste aspecto, os 
programas que indicam maior possibilidade de cooperação estão distribuídos na posição central da rede, e os programas que indicam maior particularidade estão posicionados nas extremidades.

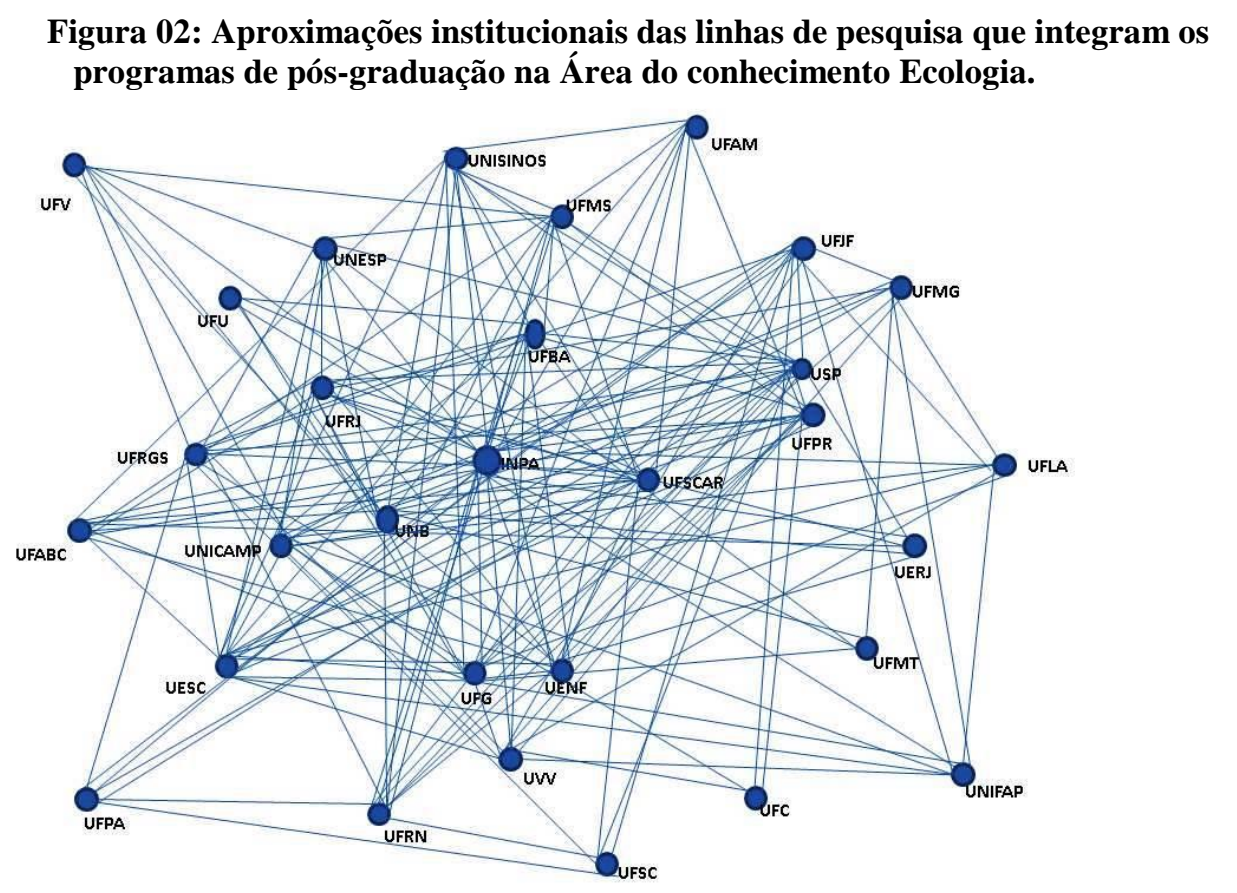

Fonte: CAPES.

De acordo com os dados do estudo, trinta (30) universidades possibilitaram a cooperação em diversas regiões do Brasil. Na representação acima, as Universidades destacadas na posição central expressam maior intensidade dos vínculos e estão situadas no grupo A (INPA, UNB, USCAR, UNICAMP). Este grupo indica grande potencial de cooperação no conjunto total das linhas de pesquisa que integram seus programas. $\mathrm{O}$ grupo B (UFRJ, UFBA, UFMS, UFPR, USP, UENF, UFG, UFRGS, UFU, UNESP) indica as universidades que dispõem de um médio vínculo e o grupo C (UESC, UVV, UFJF, UFRN, UFABAC, UNISINOS, UFMG, UERJ, UFMT, UFC, UFV, UFAM, UFLA, UNIFAP, UFSC, UFPA) expressa as universidades posicionadas mais afastadas da rede de relações, que sugerem pouco vínculo com as demais.

Entendemos que há oportunidades de formação de redes de cooperação na Área do conhecimento Ecologia; por exemplo, os grupos A e B apresentam uma grande possibilidade de cooperação entre as instituições que possuem linhas semelhantes. Neste caso, a relação acima esboça uma dimensão eco-organizadora, pois as linhas de pesquisa são formadas por grupos de indivíduos diferentes que frequentam instituições distribuídas distintas geograficamente, mas que podem interagir 
epistemologicamente por se dedicarem às linhas de pesquisa semelhantes. Por isso, a cooperação entre as linhas de pesquisa fortalece não só uma área que se dedica a um estudo específico, mas pode eleva o nível de consciência dos pesquisadores que se dedicam à linha. Morin (2011, p.81) pressupõe que "um ser vivo extrai informações do seu ambiente a fim de adaptar as suas ações. O ambiente não traz as informações, mas as condições de extração das informações; por isso mesmo cria as condições do conhecimento vivo". Neste sentido, chamamos a atenção para o princípio da auto-ecoorganização, proposto por Morin (2011), pois, ao mesmo tempo em que o autor produz a obra, ele se auto-eco-produz, e dá vida à linha de pesquisa à qual dedicou seus estudos. Compartilhar linhas comuns pode proporcionar que sujeitos e pesquisadores estejam abertos àquilo de que se "alimentam" e que transformam. Refletindo sobre esse entendimento, tomamos como exemplo a própria ciência, pois esta é uma construção histórica que inclui as formações sociais, ações entre o homem e o ambiente, na qual o homem como sujeito constrói a relação entre a teoria e a prática, entre o pensar e o atuar, em processos cognitivo-transformadores do ambiente (GAMBOA, 2012).

Em paralelo, Fleck (apud Condé, 2012, p.12) compartilha deste pensamento, pois considera que a ciência é uma atividade coletiva que visa a produção coletiva: "a produção e a validação do conhecimento científico não podem ser realizadas afastadas da sociedade ou da cultura". Em um dos textos de Fleck (1946), o autor indica que a ciência é preenchida por fenômenos culturais, complexos e coletivos, e a define como uma estrutura organizada, conectada com modalidades de comunicação e cooperação (GAMBOA, 2012). Em consequência, sustentamos que mapear a possível cooperação entre as instituições que partilham das mesmas linhas de pesquisa produz uma ciência que circula entre os especialistas e seu público por meio de um coletivo de pensadores. Gamboa (2012, p.23) sugere que "a circulação dos fatos científicos é inicialmente uma fonte de inovação no interior da ciência". Consideramos que propor uma rede de relações entre as universidades dá novas oportunidades de descobertas e criação de novos fatos às áreas de estudo, proporcionando uma transformação de um novo estilo de pensamento.

\section{CONSIDERAÇÕES FINAIS}

As discussões apresentadas no estudo evidenciam que a pós-graduação na Área do conhecimento Ecologia está em todas as regiões brasileiras. Não evidenciamos um vazio geográfico em nenhuma região, mas as regiões Norte e Nordeste possuem menor 
número de programas. Neste aspecto a região Sudeste é a que mais contém programas de pós-graduação nesta Área.

A partir dos dados levantados, há três linhas de pesquisa que concentram a maior possibilidade de redes de cooperação entre os programas: ecologia de populações e comunidades; ecologia e conservação e ecologia e manejo da biodiversidade. Esta observação é um indicio de estas linhas vem consolidando os estudos na Área do conhecimento Ecologia.

Destacamos que aproximar as linhas comuns diminui a 'distância' entre as instituições distribuídas regionalmente pelo Brasil, podendo oportunizar que as linhas mais consolidadas possam cooperar com as linhas menos consolidadas. Porém, para que isso aconteça, Moraes (2013) indica que devem ser formuladas políticas públicas específicas que induzam a cooperação.

As comunidades científicas são ambientes que favorecem a cooperação, pois nestes espaços são discutidos interesses comuns aos pesquisadores. Um conhecimento que é discutido em um coletivo induz a sua propagação e fortalece uma linha de investigação. Isso pode indicar as linhas que necessitam de mais esforços de pesquisas dentro da pós-graduação na Área do conhecimento Ecologia. Entendemos que a cooperação proporciona um novo movimento entre as comunidades de investigação no interior da ciência ecológica, proporcionando um diálogo compartilhado entre seus membros.

\section{REFERÊNCIAS BIBLIOGRÁFICAS}

BARDIN, Laurence. Análise de conteúdo. São Paulo: Edições 70, 2011.

BOMBASSARO, Luiz C. Ciência e mudança conceitual: notas sobre epistemologia

e história da ciência. Porto Alegre: [s.n.], EDIPUCRS. 1995. 124p.

BORGES-ANDRADE, J. E. Em busca do conceito de linhas de Pesquisa. Revista de

Administração Contemporânea RAC, v. 7, n. 2, Abr./Jun. 2003: 157-170.

CAPES, 2014. COORDENAÇÃO DE APERFEIÇOAMENTO DE PESSOAL DE NÍVEL SUPERIOR (CAPES). Mestrado/doutorados Reconhecidos. Disponível em:< http://conteudoweb.capes.gov.br/conteudoweb/ProjetoRelacaoCursosServlet?acao=pesq uisarArea\&identificador=7\# >Acesso em: 26/08/2014. 2014 a. COORDENAÇÃO DE APERFEIÇOAMENTO DE PESSOAL DE NÍVEL SUPERIOR (CAPES). Relação de Cursos Recomendados e

Reconhecidos/Área Biodiversidade. Disponível em: < http://conteudoweb.capes.gov.br/conteudoweb/ProjetoRelacaoCursosServlet?acao=pesq uisarIes \&codigoArea $=20500009 \&$ descricaoArea $=\&$ descricaoAreaConhecimento $=\mathrm{ECO}$ LOGIA\&descricaoAreaAvaliacao=BIODIVERSIDADE $>$ Acesso em: 10/08/2014a. 
2014b. COORDENAÇÃO DE APERFEIÇOAMENTO DE PESSOAL DE NÍVEL SUPERIOR (CAPES). Relação de Cursos Recomendados e

Reconhecidos/Área Avaliação. Disponível em:

http://conteudoweb.capes.gov.br/conteudoweb/ProjetoRelacaoCursosServlet?acao=pesq uisarAreaAvaliacao. Acesso em: 10/08/2014b.

CONDÉ, Mauro Lúcio Leitão. Ludwik Fleck: Estilos de Pensamento na ciência. Mauro Lúcio Leitão Condé (org.). Belo Horizonte, MG: Fino Traço, 2012. 160p. GAMBOA, Sílvio, A. S. A Formação do pesquisador na educação e as tendências epistemológicas. In: GAMBOA, Sílvio, A. S. Pesquisa em Educação: métodos e metodologias. $2^{\circ} \mathrm{ed}$. Chapecó: Argos, 2012. 212p.

GAMBOA, S. A. S. As Condições da Produção Científica em Educação: do modelo de áreas de concentração aos desafios das linhas de pesquisa. ETD - Educação Temática Digital. Campinas, SP, v.4, n.2, 2003. p.78-93.

CONDÉ, Mauro. L. L. Ludwik Fleck: Estilos de Pensamento na ciência. Mauro Lúcio Leitão Condé (org.). Belo Horizonte, MG: Fino Traço, 2012. 160p.

FLECK, Ludwick. Entstehung und Entwicklung einer wissenschaftlichen Tatsache Einfuhrung in die Lehre vom Denkstil und Denkkollek tiv. Frankfurt am Main, Suhrkamp Verlag, 1980. (trad. esp. La génesis y el desarolllo de um hecho científico Introducción a la teoria del estilo de pensamiento y del coletivo de pensamento. Madrid, Alianza, 1986.

FRENCH, Steven. Ciência: conceitos-chave em filosofia. Porto Alegre: Artmed, 2009. $156 \mathrm{p}$.

KUHN, Thomas S. A estrutura das revoluções científicas. 10 ed. São Paulo:

Perspectiva, 2009. 260 p.

MORAES, M. H. M. Distribuição geográfica da pós-graduação e da produção científica em Educação e suas relações com os indicadores sociais: uma abordagem cientométrica em escala mesorregional. Dissertação. Universidade Federal do Rio Grande. Rio

Grande, 2013.

MORIN, Edgar. Ciência com consciência. Maria D. Alexandre e Maria Alice Sampaio Dória (trad.) revista e modificada pelo autor $-8^{\circ} \mathrm{ed}$. - Rio de janeiro: Bertrand Brasil, 2005 350p.

MORIN, Edgar. O Método 2: A vida da vida. Trad. Marina Lobo. Porto Alegre: Sulina, 2011. $4^{\circ} \mathrm{ed}$.

NETO, R. Ivan. Prospectiva da Pós-Graduação no Brasil (2008 - 2022). Revista

Brasileira de Pós-Graduação, Brasília, v. 7, n. 12, p. 58 - 79, julho de 2010. PARREIRAS. Márcia Maria Martins. LUDWIK FLECK E A HISTORIOGRAFIA DA CIÊNCIA: diagnóstico de um estilo de pensamento segundo as Ciências da Vida. 2006. 204 f. Dissertação - Programa de Pós-graduação em História, Universidade Federal de Minas Gerais, Belo Horizonte, 2006. Disponível em: < http://www.bibliotecadigital.ufmg.br/dspace/bitstream/handle/1843/VCSA-

6XTGF7/disserta_ao_m_rcia_maria_martins_parreiras.pdf? sequence=1 $>$. Acesso em: 27 nov. 2012.

SCHNELLE, Thomas. "Microbiology and philosophy of science; Lwów and the German holocaust: stations of a life - Ludwik Fleck 1896-1961". In: COHEN, R. S. \& SCHNELLE, T. (Ed.). Cognition and Fact: materials on Ludwik Fleck. New York: Kluwar Academic Publishers, 1986a. p.3-36. 